\title{
Comentarios
}

\section{Paradigmas predominantes en la economía, la política y la cultura ${ }^{1}$}

¿Qué se quiere decir cuando se habla de "paradigma"? En un sentido amplio, un paradigma es un marco de conceptos, valoraciones y normas - todo ello coherente entre sí- que sirve de horizonte de interpretación y explicación de un ámbito determinado de la realidad. Por supuesto que ante un mismo ámbito de realidad se pueden dar distintos paradigmas de comprensión y explicación, de igual fuerza conceptual, valorativa y normativa, con lo cual se tienen paradigmas opuestos y en competencia.

La oposición y competencia entre paradigmas por lo general se resuelve a favor de uno de ellos, que se convierte en dominante - porque explica más cosas, porque es más convincente, etc.-. Es decir, en el más ampliamente aceptado por los grupos sociales involucrados en la comprensión y explicación de tal o cual ámbito de realidad. Los demás paradigmas no desaparecen, pero quedan en una posición de subordinación en relación con el paradigma dominante.

Asimismo, hay tantos paradigmas como realidades por explicar y comprender existen. Paradigmas científicos, paradigmas filosóficos, paradigmas teológicos... Por lo demás, donde más fuerza ha cobrado la idea de paradigma es en el terreno de las ciencias naturales, gracias al aporte decisivo de Thomas Kuhn, quien llegó a formular la definición clásica de paradigma: "realizaciones científicas universalmente reconocidas que, durante cierto tiempo, proporcionan modelos de problemas y soluciones a una comunidad científica... Los paradigmas obtienen su status como tales, debido a que tienen más éxito que sus competidores para resolver unos cuantos problemas que el grupo de profesionales ha llegado a conocer como agudos"2.

¿De cuáles paradigmas nos vamos a ocupar aquí? Nos vamos a ocupar de los paradigmas predominantes en los ámbitos económico, político y cultural. Es decir, nos vamos a ocupar de los marcos conceptuales, valorativos y normativos que en la actualidad son los dominantes en los tres ámbitos señalados.

I. En el ámbito económico, el paradigma dominante es el paradigma neoliberal. Los paradigmas subordinados son, por un lado, el paradigma del Estado de bienestar y, por el otro, el paradigma del socialismo real. El primero de ellos tiene como eje básico un modelo de economía mixta que permite la intervención estatal en la economía y los programas de seguridad social vistos como un derecho de los ciudadanos que el Estado debe garantizar. Como dice Gloria Regonini: el principio fundamental del Estado de bienestar es que "independientemente de sus ingresos, todos los ciudadanos -en cuanto tales - tienen derecho a ser protegidos -

1. Texto ampliado de la charla ofrecida por el autor a un grupo de hermanos maristas de sudamérica, México y España, reunidos en la casa de retiro "Brisas del Carmelo", en Santa Tecla (La Libertad), del 26 de julio al 9 de agosto de 1999.

2. Th. Kuhn, La estructura de las revoluciones cientificas, México, FCE, 1985, pp. 13 y 51-52. 
con pagos en efectivo o con servicios- en situaciones de dependencia de largo plazo (vejez, invalidez...) o de breve plazo (enfermedad, desempleo, maternidad...)"3.

Por su parte, el segundo paradigma —el del socialismo real- se articula en torno a un Estado poderoso, el cual ejerce un control casi total sobre la sociedad y la economía, sofocando las actividades socioeconómicas autónomas y ajenas a la tutela estatal. Piezas claves del paradigma económico del socialismo real, tal como éste se concretó en el llamado "modelo estalinista de desarrollo", son las siguientes: "( $a$ ) plan central elaborado y administrado por una burocracia rígidamente jerarquizada; (b) el instrumento de control principal era el 'balance material' en el que se registran los flujos de insumos y productos: los precios sólo se consideran como unidades contables; (c) se suponía que mientras mayor era la tasa de acumulación mayor sería el crecimiento del producto: la rama de bienes de producción debía crecer siempre más rápido que los de consumo; $(d)$ en agricultura, se pensaba que la gran propiedad era siempre más eficiente que la pequeña, y el desarrollo de esa rama debía subordinarse a las necesidades de la industrialización"4.

Ambos paradigmas —el del Estado de bienestar y el del socialismo real- ciertamente no han desaparecido, pero su atracción conceptual, normativa y valorativa ha perdido mucha de la fuerza y presencia que tuvieron en décadas anteriores; esa pérdida de fuerza y presencia no es ajena al influjo creciente del paradigma neoliberal durante la década de los años noventa.

Los componentes básicos del paradigma neoliberal son los siguientes:

(a) El capitalismo no sólo es el modelo económico que ha triunfado sobre otros modelos económicos — constatación de hecho-, sino que es el mejor, el más acorde con las necesidades y preferencias del ser humano individual —valoración moral-. (b) La economía funciona mejor, es más eficiente y genera más riqueza si está regida por las fuerzas del mercado - oferta y demanda-.

(c) El mercado no debe tener interferencias de ningún tipo, sino todo lo contrario. Esto quiere decir que el papel del Estado en la economía debe reducirse al mínimo - a través de la privatización de las empresas públicas y la eliminación de puestos de trabajo en el sector público-.

(d) Para que la economía pueda despegar, después de una situación de estancamiento, debe pasar por un período de saneamiento. El mecanismo adecuado para ello es el "ajuste estructural": liberación de los controles de precios, reducción de los gastos sociales y congelamiento de los salarios mínimos en el sector público y privado.

(e) El mercado debe regir las relaciones económicas a nivel mundial, por lo cual es necesario suprimir los obstáculos que se oponen a ello en cada país. Se trata de la liberación comercial, la cual está encaminada a "abrir" las economías locales a la llegada de bienes y servicios provenientes del exterior.

II. En el ámbito político, el paradigma dominante es el paradigma de la democracia. Los paradigmas subordinados son el paradigma de la democracia popular y el paradigma del autoritarismo. El primero de estos dos paradigmas posee, como uno de sus rasgos distintivos, la apelación a una participación de todos los miembros de la sociedad en las decisiones fundamentales de una nación, sin intermediación alguna de representantes que hablan en nombre de ellos. La idea se propagó fuertemente luego de la implantación de regímenes socialistas en Europa del Este, después de la segunda guerra mundial. Varios de los nuevos regímenes no tardaron en ser bautizados por los órganos de propaganda oficiales como "democracias populares", en las que cristalizaba lo más propio de la democracia como "poder del pueblo". Con todo, el gran escenario donde se fraguó lo mejor de este paradigma fue en Cuba revolucionaria. Y

3. G. Regonini, "Estado de bienestar". En N. Bobbio, N. Matteucci, G. Pasquino, Diccionario de política, México, Siglo XXI, 1998, p. 553.

4. E. Semo, Crónica de un derrumbe. Las revoluciones inconclusas del Este, México, Proceso-Grijalbo, 1991, pp. 183. Para ampliar en los componentes de este paradigma, ver M. Gorbachev, Perestroika, México, Diana, 1991; M. Reiman, "El estalinismo como fenómeno de la sociedad soviética". En F. Claudín (Comp.), La perestroika ¿Hacia donde va la Unión Soviética, Madrid, Editorial Pablo Iglesias, 1990, pp. 33-51. 
dos de los mejores propugnadores de este paradigma fueron Fidel y Raúl Castro, quienes encontraron en Marta Hameker a una excelente sistematizadora y divulgadora del mismo. En su libro Cuba: dictadura o democracia (1975), Hameker recoge las opiniones de dos de los forjadores del paradigma de la democracia popular.

Estas son las palabras de Raúl Castro: "cuando un Estado como el nuestro representa los intereses de los trabajadores, cualesquiera sean su forma y estructura, resulta un tipo de Estado más democrático que ningún otro tipo que jamás haya existido en la historia, por-

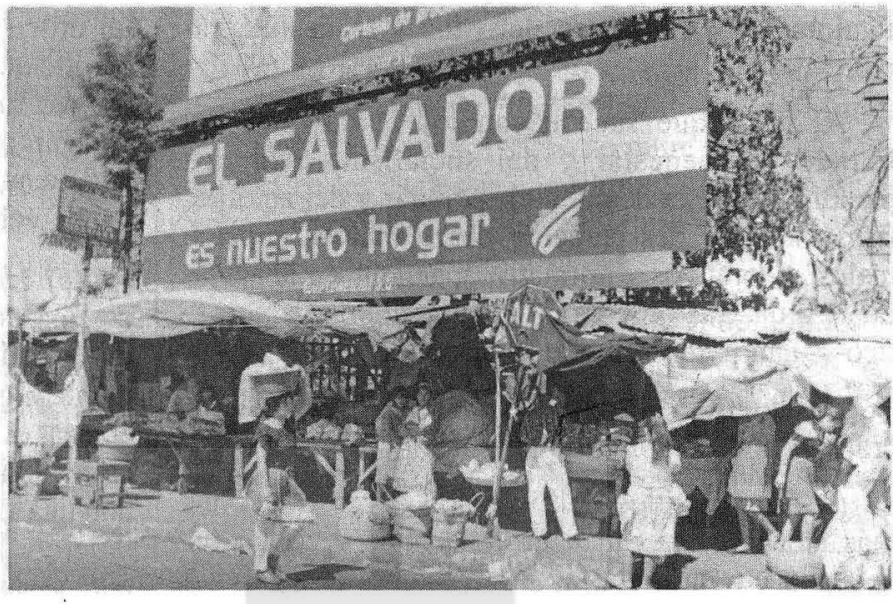
que el Estado de los trabajadores, el Estado que construye el socialismo es, bajo cualquier forma, un Estado de las mayorías, mientras que todos los estados anteriores han sido los estados de las minorías explotadoras... [en el Estado revolucionario] las masas han participado en la discusión de todas las cuestiones más importantes de la Revolución, de sus leyes principales y ahora comienzan a participar en la discusión de los planes económicos hasta nivel de unidades de producción y servicios"'. Por su parte, Fidel Castro dice lo siguiente: "no hay ninguna medida fundamental aquí, ninguna ley fundamental que no se discuta con todo el pueblo... De manera que la dictadura es la dictadura de la inmensa mayoría del pueblo. Por eso tú le puedes llamar dictadura o le puedes llamar democracia obrera o democracia popular"6.

Finalmente, Marta Harneker remata: "así como el Estado cubano ha sido una dictadura para la contrarrevolución, ha sido para el pueblo - aun sin la presencia de instituciones respresentativas - un Estado esencialmente democrático. Durante todos estos años ha representado y defendido los intereses de los trabajadores, de la gran mayoría del pueblo cubano $\mathrm{y}$, al mismo tiempo, no ha tomado ninguna medida revolucionaria importante sin consultar a la masa a través de diferentes mecanismos"?.

El segundo de los paradigmas —el del autoritarismo- tiene como eje básico el control verticalista, amparado en la fuerza, de la sociedad. Aquí lo importante no es alentar la participación de todos en todo, sino más bien lo opuesto: desarticular los mecanismos de participación social y desmotivar a los ciudadanos acerca de cualquier compromiso colectivo de cambio social. Entre otros, los siguientes aspectos son claves en el paradigma autoritario: (a) a la comunidad política no se le reconoce autonomía ni independencia; (b) debilidad o ausencia de estructuras de movilización políticosocial; (c) no se sostiene en elaboraciones ideológicas articuladas, sino en referentes ambiguos como patria, orden, nación, autoridad y jerarquía; (d) ausencia de normas bien definidas, lo cual permite el control social y debilita al ciudadano frente al poder autoritario; y (e) personificación del poder, por la visibilidad del líder, o por las pocas personas que detentan el poder ${ }^{\text {s }}$.

En suma, "el pensamiento autoritario -como dice Mario Stoppino- no se limita a propugnar por una organización jerárquica de la sociedad política sino que convierte a esta organización en el principio político exclusivo para conseguir lo que se considera el bien supremo: el orden. Sin un ordenamiento rígidamente jerárquico, la sociedad va

5. Palabras de Raúl Castro en la clausura de un seminario para delegados del Poder popular, 22 de agosto de 1974. En M. Harnecker, Cuba: dictadura o democracia, México, Siglo XXI, 1975, pp. 39-40.

6. Conferencia de prensa de Fidel Castro en la Habana, agosto de 1975. En M. Harnecker, op. cit., p. 41.

7. M. Harnecker, op. cit., p. 39.

8. Estos aspectos han sido retomados, en forma resumida, de L. Morlino, "Los autoritarismos". En G. Pasquino, et al., Manual de ciencia política, Madrid, Alianza, 1996, pp. 131-133. 
fatalmente al encuentro del caos y la desintegración"'.

Al igual que sucede con los paradigmas del Estado de bienestar y del socialismo real, los paradigmas de la democracia popular y del autoritarismo no han desaparecido como marcos conceptuales, valorativos y normativos, aunque en la actualidad —dado el predomino del paradigma democrático- han perdido fuerza y presencia.

Los componentes básicos del paradigma democrático (liberal) son los siguientes:

(a) Los partidos políticos son las instituciones más idóneas para canalizar las demandas de los diversos sectores sociales, en un marco de legalidad $y$ orden, hacia las instancias estatales encargadas de darles respuesta. Otros medios se prestan al desorden y el conflicto.

(b) Las elecciones periódicas, trasparentes, plurales y competitivas, son el mejor recurso para acceder a los puestos de dirección gubernamental. Allí donde se dan elecciones periódicas, la democracia puede considerarse establecida. Las elecciones permiten la llegada (o permanencia) de los más capaces al poder político y la salida de los menos competentes, es decir, permite la renovación política permanente.

(c) La separación de poderes - ejecutivo, legislativo y judicial- es necesaria para evitar que uno de ellos concentre demasiado poder en sus manos, con lo cual se pueda dar pie al despotismo. Es decir, la separación de poderes permite el control y el balance entre las instancias fundamentales de decisión estatal. Allí donde hay un poder único - civil o militar - no hay democracia.

(d) El individuo es sujeto de una serie de derechos que no pueden ser violados so pena de atentar contra la naturaleza humana. Esos derechos son, básicamente, los siguientes: la libertad de posesión, la libertad de pensamiento y expresión, la libertad de asociación y la libertad de dotarse de un orden político que garantice esos derechos. La democracia es ese orden político, un orden político que tiene como una de sus principales funciones garantizar que todos los miembros de la sociedad pueden gozar, sin discriminación alguna, de los derechos señalados.

(e) La democracia es una democracia política no una democracia social. Como tal, la democracia (política) ha sido diseñada para evitar el despotismo y garantizar que el orden político no atente contra el individuo, privándolo de su libertad u obligándolo a hacer cosas contrarias a su naturaleza humana. Eso que se llama "democracia social" se refiere a la igualdad económica y la justicia distributiva, las cuales no son el asunto central de la democracia $y$, además, no necesariamente tienen que estar asociadas a ella (aunque pueden estarlo).

III. En el ámbito cultural, el paradigma dominante es el paradigma neoconservador. Los paradigmas subordinados son el paradigma crítico y el paradigma postmoderno. El primero de ellos apela a la importancia de la razón no sólo para orientar la vida humana, sino para apuntalar cambios históricos de gran envergadura. Para los teóricos críticos -entre quienes figuran intelectuales del calibre de J. Habermas, M. Horkheimer, T.W. Adorno y H. Marcuse - la razón "es capaz, por su naturaleza, de negatividad. Es decir, la razón critica la realidad de una manera que prepara el terreno para la reconstrucción de la historia"1". Y H. Marcuse, uno de los principales gestores de este paradigma, dice lo siguiente: "bajo el nombre de razón se concibe la idea del ser auténtico... La razón representa la más alta potencialidad del hombre y la existencia; ambos convienen recíprocamente"11.

Dicho brevemente, desde el paradigma crítico se perfila una propuesta de emancipación racional-ilustrada —esto es, no tradicional-religiosa--, orientada hacia la transformación social ${ }^{12}$. Sus portavoces —dice J.M. Mardones- "sin ingenuidades ni falsas

9. M. Stoppino, “Autoritarismo". En N. Bobbio, N. Matteucci, G. Pasquino, Diccionario de política, México, Siglo XXI, 1998, p. 126.

10. G. Friedman, La filosofía política de la escuela de Frankfurt, México, FCE, 1986, pp. 117-118.

11. H. Marcuse, "Philosophy and critical theory". Citado por G. Friedman, op. cit., p. 118.

12. Ver L.A. González, "Neoconservadores, posrmodernos y teóricos críticos". Metapolítica (México), No. 1, enero-marzo de 1997, pp. 72-81. 
ilusiones, quieren proseguir el programa ilustrado que pretende hacer de la razón y el sujeto elementos primordiales de la construcción de una sociedad justa, racional y humana"13.

Mientras tanto,el paradigma postmoderno se centra en la defensa de la sensibilidad individual, la cual - a juicio de los forjadores del paradigma- está sometida a los embates de la razón totalizante. Es decir, en este paradigma se rechaza frontalmente el papel pretendidamente emancipador de la razón, a la que más bien se acusa de legitimar, con su ambición totalizante, ordenamientos sociales, económicos y políticos contrarios a la libertad humana individual. En general, los autores que han forjado este paradigma - por ejemplo, G. Vattimo y J.F., Lyotard- insisten en que la ambición totalizante de la razón, expresada en los sistemas de pensamiento metafísicos, ha ejercido violencia contra el individuo y su sensibilidad. "La metafísica resulta desacreditada además, y antes que nada dice Vattimo-, porque la indiferencia hacia la vida del individuo, hacia los derechos de lo contingente y lo caduco, es lo que desde siempre ha constituido su contenido real"14. La defensa de lo sensible aparece con claridad en este otro texto de Vattimo: "no sólo es violencia metafísica tapar y borrar los derechos de lo sensible y de lo caduco en la afirmación de esencias universales y abstractas; igualmente violento y fetichista es despojar a lo sensible de su dimensión de alteridad"15.

En resumen, tanto el paradigma crítico como el paradigma postmoderno, aunque gozan todavía de una presencia y aceptación en determinados círculos intelectuales y artísticos, no están tan ampliamente difundidos entre grupos sociales diversos como lo está el paradigma neoconservador, el cual, al cierre del siglo $\mathrm{XX}$, con los temores y expectativas que inevitablemente se asocian al fin de un milenio, ha encontrado un clima propicio para que sus adalides propaguen, agresivamente y sin reservas, su credo.

Los elementos característicos del paradigma neoconservador son los siguientes:

(a) El ser humano no tiene más asidero que la $\mathrm{Fe}$ para orientarse y tomar las decisiones fundamentales de su vida. Esa Fe se nutre de fuentes religiosas, en las cuales se encuentran, casi acabadas, no sólo las respuestas a los problemas que le aquejan, sino las normas de conducta correctas y buenas.

(b) El mal acecha permanentemente a la humanidad, expresado en guerras, avaricia, sexo, drogas, música metálica, tolerancia, etc. El mal tiene que ser combatido por los "buenos", los que han tenido contacto con las fuentes "divinas" y están dispuestos a lanzarse a una cruzada para convertir a los infieles. Se trata de un enfrentamiento del bien contra el mal; de los fieles contra los infieles.

(c) No cualquiera puede luchar contra el mal. Para ello hay que ser tocado por el "don", es decir, ser seleccionado por un Ser superior. ¿Cómo se sabe quién ha sido seleccionado (elegido)? Primero, por su "dominio" de las fuentes. Segundo, por su estilo de vida: austero, recto, ahorrativo, miembro de una familia estable y amante del orden. Tercero, por su determinación de combatir activamente a quienes se propagan valores y estilos de vida distintos a los seguidos por los buenos: a los que tienen familias desorganizadas, a quienes promueven (o discuten sobre) el aborto, a las lesbianas y los homosexuales, a las feministas, a quienes se divorcian, a quienes les gusta la música metálica, etc.

(d) En las versiones religiosas católicas, el neoconservadurismo se expresa como una vuelta hacia la vida interior, un moralismo y un puritatanismo excerbados. Un respeto y sumisión a la jerarquía eclesial, una defensa de la armonía familiar, la paz interior, el respeto a las autoridades políticas y la condena de todo aquello que socave la estabilidad social ${ }^{16}$.

En conclusión, los paradigmas dominantes en el mundo actual son, en el plano económico, el neoliberal; en el plano político, el democrático; y

13. J.M. Mardones, Postmodernidad y cristianismo, Santander, Sal Terrae, 1988, p. 53.

14. G. Vattimo, "Metafísica, violencia, secularización". En G. Vattimo (Comp.), La secularización de la filosofía. Hermenéutica y posmodernidad, Barcelona, Gedisa, 1992, p. 69.

15. Ibid., p. 70.

16. Hay quienes ven en los procesos de betatificación propiciados por el Papa Juan Pablo II un aspecto más del modelo neoconservador que se ha impuesto en el Vaticano. Ver "Fábrica de santos", El País Digital, 23 de agosto de 1999. 
en el plano cultural, el neoconservador. Es ineludible habérselas con esos paradigmas a la hora de comprometerse con un proyecto determinado de cambio social, económico, político o cultural. Pero no se trata de aceptarlos ciega o acríticamente, sino como marcos conceptuales, normativos y valorativos cuya revisión y cambio es posible, siempre que se propongan alternativas realistas y factibles.

Así, el proyecto neoliberal debe ser examinado en todas sus implicaciones económicas y sociales. La ceguera ante el impacto sobre los sectores mayoritarios de la población de unas políticas económicas y sociales, que apuntan exclusivamente a garantizar el éxito de los mecanismos del mercado, puede traer consigo enormes costos socio-políticos, como ya se vislumbra en las movilizaciones y las protestas que acompañan a los procesos de privatización y desmantelamiento del Estado. El influjo neoconservador también debe ser abordado con la mayor atención posible. Y, sobre todo, estar alertas para no sucumbir a sus llamados redentores y a su espíritu de cruzada. Ahora más que nunca se requiere de la energía y la lucidez de la razón crítica para no dejarse embaucar por quienes, a cambio de la salvación, nos piden no sólo que renunciemos a nuestra libertad
- de elegir el propio estilo de vida, de pensar, de criticar-, sino que obliguemos a otros a que renuncien a la suya.

Por último, en el caso de la democracia, es preciso retomar aquellas críticas que destacan lo endeble que puede resultar, en sociedades con una mayoría de ciudadanos que viven en la pobreza, una democracia que no sea, a la vez que política, también social. Asimismo, no hay que perder de vista a aquellos que todavía levantan tanto las banderas de la democracia popular como del autoritarismo como alternativas, la primera, a una democracia traicionada por una "representividad", que imposibilita la participación real de los ciudadanos en la conducción política de la sociedad; y, la segunda, como solución al desorden que traen consigo las disputas políticas, la dispersión de opiniones y decisiones, la tolerancia y la libertad de crítica propias de los regímenes democráticos. Estas ideas, aunque hoy por hoy no den muestras de tener la suficiente fuerza como para restar adeptos al paradigma democrático, bien podrían en el futuro (y en contextos golpeados por la crisis económica, la pobreza y el malestar) prender como en el pasado.

Luis Armando González 